\title{
Added value of diffusion-weighted MRI in assessment of pleural lesions
}

\author{
Youssriah Yahia Sabri', Ikram Hamed Mahmoud ${ }^{2}$, Lamis Tarek El-Gendy ${ }^{3}$, Mohamed Raafat Abd El-Mageed ${ }^{1}$ and \\ Sally Fouad Tadros ${ }^{1 *}$ (D)
}

\begin{abstract}
Background: There are many causes of pleural disease including variable benign and malignant etiologies. DWl is a non-enhanced functional MRI technique that allows qualitative and quantitative characterization of tissues based on their water molecules diffusivity. The aim of this study was to evaluate the diagnostic value of DWI-MRI in detection and characterization of pleural diseases and its capability in differentiating benign from malignant pleural lesions.

Results: Conventional MRI was able to discriminate benign from malignant lesions by using morphological features (contour and thickness) with sensitivity $89.29 \%$, specificity $76 \%$, positive predictive value $89 \%$, negative predictive value $76.92 \%$, and accuracy $85.37 \%$. ADC value as a quantitative parameter of DWI found that ADC values of malignant pleural diseases were significantly lower than that of benign lesions $(P<0.001)$. Hence, we discovered that using ADC mean value of $1.68 \times 10^{-3} \mathrm{~mm}^{2} / \mathrm{s}$ as a cutoff value can differentiate malignant from benign pleural diseases with sensitivity $89.3 \%$, specificity $100 \%$, positive predictive value $100 \%$, negative predictive value $81.2 \%$, and accuracy $92.68 \%(P<0.001)$.

Conclusion: Although DWI-MRI is unable to differentiate between malignant and benign pleural effusion, its combined morphological and functional information provide valid non-invasive method to accurately characterize pleural soft tissue diseases differentiating benign from malignant lesions with higher specificity and accuracy than conventional MRI.
\end{abstract}

Keywords: DWI, Pleural lesions, MRI

\section{Background}

There are many causes of pleural disease including variable benign and malignant etiologies [1]. Pleural diseases are generally classified into non-neoplastic and neoplastic diseases. Non-neoplastic diseases include pleural effusion and pleural thickening (focal or diffuse), while neoplastic diseases are either benign (e.g., lipoma and solitary fibrous tumor) or malignant (most commonly malignant pleural mesothelioma and metastasis) [2]. Although the most frequent radiographic findings of pleural disease are pleural effusion or thickening, etiological diagnosis is challenging [3].

\footnotetext{
* Correspondence: sallyfouad86@gmail.com

${ }^{1}$ Faculty of Medicine, Cairo University, Kasr Al-Ainy Faculty of Medicine, Al-Manial, Cairo 11559, Egypt

Full list of author information is available at the end of the article
}

Routinely, conventional radiography or CT and not MRI are used to identify pleural diseases [4]. However, MRI has an additional benefit in particular cases (e.g., malignant pleural mesothelioma), being superior to CT and other imaging modalities in depiction of chest wall, mediastinum, and diaphragmatic invasion [5].

MRI has recently enhanced the diagnostic competence of pleural lesions, owing to its ability to combine morphological and functional information, so it is able to differentiate benign from malignant pleural diseases, in addition to providing further data in malignant pleural diseases as regards their prognosis and treatment response [4]. Diffusion-weight images (DWI) is not are a non-enhanced functional MRI technique that allows characterization of tissues based on their water molecules diffusivity. DWI analysis is performed by

\section{Springer Open}

(อ) The Author(s). 2021 Open Access This article is licensed under a Creative Commons Attribution 4.0 International License, which permits use, sharing, adaptation, distribution and reproduction in any medium or format, as long as you give appropriate credit to the original author(s) and the source, provide a link to the Creative Commons licence, and indicate if changes were made. The images or other third party material in this article are included in the article's Creative Commons licence, unless indicated otherwise in a credit line to the material. If material is not included in the article's Creative Commons licence and your intended use is not permitted by statutory regulation or exceeds the permitted use, you will need to obtain permission directly from the copyright holder. To view a copy of this licence, visit http://creativecommons.org/licenses/by/4.0/. 
qualitative and quantitative methods [6]. Qualitative (visual) assessment of DWI is based on the restriction of water movement in highly cellular tissues, as tumors, causing them to appear bright on DWI [7]. Quantitative analysis of DWI is achieved by calculating its apparent diffusion coefficient (ADC) value which is inversely proportional to tissue cellularity. Low ADC values are observed in highly cellular tissues in which water diffusion is restricted, while high ADC values reflect free diffusion of water molecules [8]. The DWI should always be interpreted in combination with the ADC maps and the conventional MRI sequences to prevent diagnostic pitfalls [6].

The aim of this study was to evaluate the diagnostic value of DWI-MRI in detection and characterization of pleural diseases and its capability in differentiating benign from malignant pleural lesions.

\section{Methods}

Our local institutional review board approved this prospective cross-sectional study, and written informed consent was obtained from all participants or their authorized representatives.

\section{Study population}

This study included 57 patients ( 36 males and 21 females; their ages ranged from 10 to 81 with mean age of 48.53 years) referred to the Radiology Department during the period from March 2019 to November 2020 to undergo DWI-MRI of the chest. The most common presenting symptoms were chest pain and dyspnea; other symptoms such as cough and weight loss were less common, as shown in Table 1.

\section{Inclusion criteria}

Patients with pleural thickening, pleural effusion, or pleural masses as identified on CT.

\section{Exclusion criteria}

Patients having a contra-indication to MRI, e.g., pacemakers, claustrophobia, cochlear implants, metallic foreign bodies, or aneurysm clips.

Table 1 Numbers and percentages of presenting clinical symptoms

\begin{tabular}{lll}
\hline Symptoms & Number of patients & Percentage \\
\hline Chest pain & 27 & $47.4 \%$ \\
Dyspnea & 33 & $57.9 \%$ \\
Cough & 12 & $21.1 \%$ \\
Weight loss & 8 & $14.1 \%$ \\
\hline
\end{tabular}

\section{MRI technique}

MRI of the chest with DWI was done using a 1.5T unit (Achieva; Philips Medical Systems, Best, The Netherlands) at our Radiology Department.

\section{Patient preparation}

Explanation of the procedure to the patient and instructing them to keep motionless and breathe calmly during the examination time.

If contrast enhanced study was recommend, $0.01 \mathrm{ml} /$ $\mathrm{kg}$ of contrast was injected by an automatic injector into a venous catheter placed in a peripheral vein.

\section{Patient position}

The patients were put in a supine position with the head directed to the scanner bore.

\section{Image acquisition}

A 16-channel phased array torso coil (Sense XL Torso; Philips Healthcare) was used to acquire axial and coronal T1 WI, axial, axial, coronal and sagittal T2 WI, axial STIR, and DWI. Respiratory gated technique was used. MR imaging parameters are listed in Table 2.

The ADC maps were calculated by the MR system via linear regression analysis of the natural $\log$ of signal intensity using all three $b$ values $\left(0,500\right.$, and $\left.1000 \mathrm{~s} / \mathrm{mm}^{2}\right)$.

\section{Image analysis}

MR images were qualitatively analyzed by visually assessing of the different pulse sequences and quantitatively assessed by measuring the ADC values of the pleural lesions.

\section{Qualitative assessment}

Pleural diseases were analyzed for their type (fluid or soft tissue), morphological features (pleural thickening classified as smooth and nodular), thickness $(<1 \mathrm{~cm}$ or $>1 \mathrm{~cm}$ ), and extent as well as the relation to the adjacent structures.

Mediastinal and hilar lymph nodes $>10 \mathrm{~mm}$ in shortaxis diameter were considered enlarged.

Each lesion signal intensity was judged on the T1, T2, and STIR WI relative to muscles in the same pulse sequence. Qualitative assessment on DWI and ADC maps was carried out by evaluating their signal intensity on the high $b$ value $\left(b=1000 \mathrm{~s} / \mathrm{mm}^{2}\right)$ DWI and comparing it to that on the corresponding ADC map.

Documentation of any associated MR imaging findings was also done.

\section{Quantitative assessment}

To measure the ADC values, the ROI (region of interest) was placed in the center of the tumor or effusion being kept as large as possible. In case of soft tissue lesions, 
Table 2 MR imaging parameters

\begin{tabular}{|c|c|c|c|c|c|c|}
\hline Sequence & $\begin{array}{l}\text { RT/ET } \\
\text { (ms) }\end{array}$ & $\begin{array}{l}\text { Direction of frequency } \\
\text { encoding }\end{array}$ & $\begin{array}{l}\text { Section thickness } \\
(\mathrm{mm})\end{array}$ & $\begin{array}{l}\text { Slice gap } \\
(\mathrm{mm})\end{array}$ & $\begin{array}{l}\text { Field of view } \\
(\mathrm{mm})\end{array}$ & Matrix \\
\hline Axial T1 WI (TSE) & $10 / 4.6$ & $\mathrm{AP}$ & 9 & 2 & $420 \times 325 \times 306$ & $\begin{array}{l}212 \times \\
179\end{array}$ \\
\hline Coronal T1 WI (TSE) & $10 / 4.6$ & $R / L$ & 9 & 1.5 & $425 \times 425 \times 208$ & $\begin{array}{l}284 \times \\
246\end{array}$ \\
\hline Axial T2 WI (TSE) & $738 / 100$ & $A P$ & 9 & 2 & $420 \times 325 \times 306$ & $\begin{array}{l}248 \times \\
167\end{array}$ \\
\hline Coronal T2 WI (TSE) & $738 / 100$ & $R / L$ & 9 & 1.5 & $425 \times 425 \times 208$ & $\begin{array}{l}284 \times \\
246\end{array}$ \\
\hline Sagittal T2 WI (TSE) & $738 / 100$ & $\mathrm{AP}$ & 8.5 & 1 & $400 \times 299 \times 284$ & $\begin{array}{l}268 \times \\
195\end{array}$ \\
\hline Axial STIR WI & $1788.3 / 20$ & $A P$ & 10 & 2 & $450 \times 333 \times 334$ & $\begin{array}{l}216 \times \\
161\end{array}$ \\
\hline \multirow[t]{2}{*}{$\begin{array}{l}\text { DWI (SS-SE-EPI-with fat } \\
\text { suppression) }\end{array}$} & \multicolumn{6}{|c|}{$\begin{array}{l}\text { Acquired in a transverse plane, using three } b \text { values; low }\left(0-50 \mathrm{~s} / \mathrm{mm}^{2}\right) \text {, intermediate }\left(500 \mathrm{~s} / \mathrm{mm}^{2}\right) \text {, and high } b \text { value } \\
\left(1000 \mathrm{~s} / \mathrm{mm}^{2}\right)\end{array}$} \\
\hline & $1407 / 66.5$ & $\mathrm{AP}$ & 9 & 2 & $420 \times 324 \times 306$ & $\begin{array}{l}140 \times \\
107\end{array}$ \\
\hline
\end{tabular}

TR repetition time, TE echo time, WI weighted image, TSE turbo spin echo, STIR short tau inversion recovery, $R / L$ right to left, $A / P$ antero-posterior, SS-SE-EPI singleshot spin-echo echo-planar imaging

the ROI was placed within the most restricted areas. While in case of effusion, the ROI was positioned in the center of the effusion to avoid the possible magnetic susceptibility artifacts from lung-fluid interfaces.

\section{Histopathological diagnosis}

Our reference for diagnosis in all patients was histopathological analysis of ultrasound or CT-guided tissue biopsies or aspiration cytology.

\section{Statistical analysis}

Data were coded and entered using the statistical package SPSS (Statistical Package for the Social Sciences) version 26 (IBM Corp., Armonk, NY, USA). Data was summarized using mean, standard deviation, median, minimum, and maximum in quantitative data and using frequency (count) and relative frequency (percentage) for categorical data. Comparisons between quantitative variables were done using the non-parametric MannWhitney test. ROC curve was constructed with area under curve analysis performed to detect best cutoff value of $\mathrm{ADC}$ for detection of malignancy. $P$ value less than 0.05 was considered as statistically significant.

\section{Results}

Thirty-six out of the $57(63.2 \%)$ patients were males and $21(36.8 \%)$ were females. The encountered pleural diseases were subdivided according to lesions types based on their imaging findings; 40 patients showed pleural effusion and 41 showed pleural thickening and neoplastic lesions.

From the 40 patients with pleural effusion, 4 (10\%) had bilateral effusion and 36 (90\%) patients had unilateral effusion; 21 (52.5\%) on the right side and 15 (37\%.5) on the left side.

According to the cytology results, 14 (40\%) patients were diagnosed with malignant pleural effusion, while the other 26 (60\%) patients had benign pleural effusion.

Morphological assessment of pleural effusion was classified according to cross-sectional imaging into either free or encysted, where 20 (50\%) patients showed free effusion and 20 (50\%) patients showed encysted effusion.

On correlating the morphological assessment with the cytology results, 10 (50\%) of the 20 patients showing encysted effusion were found to have malignant effusion and 10 (50\%) had benign effusion. On the other hand, from the 20 patient with free effusion, 14 (70\%) were benign and 6 (30\%) were malignant (Fig. 1).

According to signal intensity analysis, in 39 (97.5\%) patients, the fluid displayed low T1, bright T2, and STIR signal intensities, while in the remaining one $(2.5 \%)$ patient which had hemothorax, the fluid displayed high T1 and low T2 and STIR signals (Fig. 2).

Qualitative assessment of the DWI and ADC maps revealed that $39(97.5 \%)$ patients with pleural effusion showed no evidence of diffusion restriction, whereas the one $(2.5 \%)$ patient diagnosed with empyema showed diffusion restriction being bright on DWI with corresponding dark area on the ADC map (Fig. 3).

Pleural effusion ADC mean values ranged from $0.82 \times$ $10^{-3} \mathrm{~mm}^{2} / \mathrm{s}$ to $4.83 \times 10^{-3} \mathrm{~mm}^{2} / \mathrm{s}$ with average $3.35 \pm$ $0.78 \times 10^{-3} \mathrm{~mm}^{2} / \mathrm{s}$.

Malignant effusion ADC mean values ranged from $2.09 \times 10^{-3} \mathrm{~mm}^{2} / \mathrm{s}$ to $3.96 \times 10^{-3} \mathrm{~mm}^{2} / \mathrm{s}$ with average $3.08 \pm 0.55 \times 10^{-3} \mathrm{~mm}^{2} / \mathrm{s}$, while, benign effusion ADC 


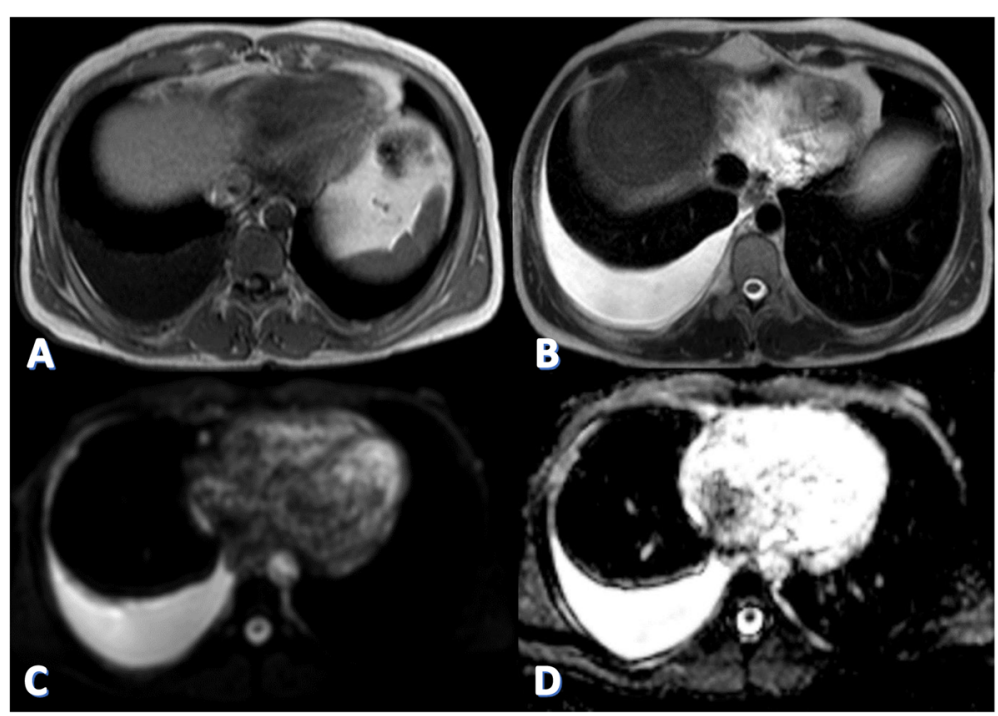

Fig. 1 a Axial T1 WI and b axial T2 WI showing right moderate pleural effusion eliciting low T1 and high T2 signal intensities. c DWI and $\mathbf{d} A D C$ map showing no evidence of diffusion restriction being bright on DWI and ADC map (ADC mean $=3.14 \times 10^{-3} \mathrm{~mm}^{2} / \mathrm{s}$ ). Ultrasound-guided aspiration cytology revealed malignant pleural effusion

mean values were between $0.82 \times 10^{-3} \mathrm{~mm}^{2} / \mathrm{s}$ and 4.83 $\times 10^{-3} \mathrm{~mm}^{2} / \mathrm{s}$ with average $3.5 \pm 0.82 \times 10^{-3} \mathrm{~mm}^{2} / \mathrm{s}$.

Hence, the ADC mean values of malignant pleural effusion were not significantly different from benign pleural effusion $(P=0.09)$ making MRI unable to differentiate between them.
From the 41 patients showing pleural thickening and neoplastic lesions, 40 (97.6\%) had unilateral lesions; 21 (51.2\%) on the right side and 19 (46.3\%) on the left side.

Patients were grouped according to histopathological diagnosis into benign pleural lesions and malignant pleural lesions.

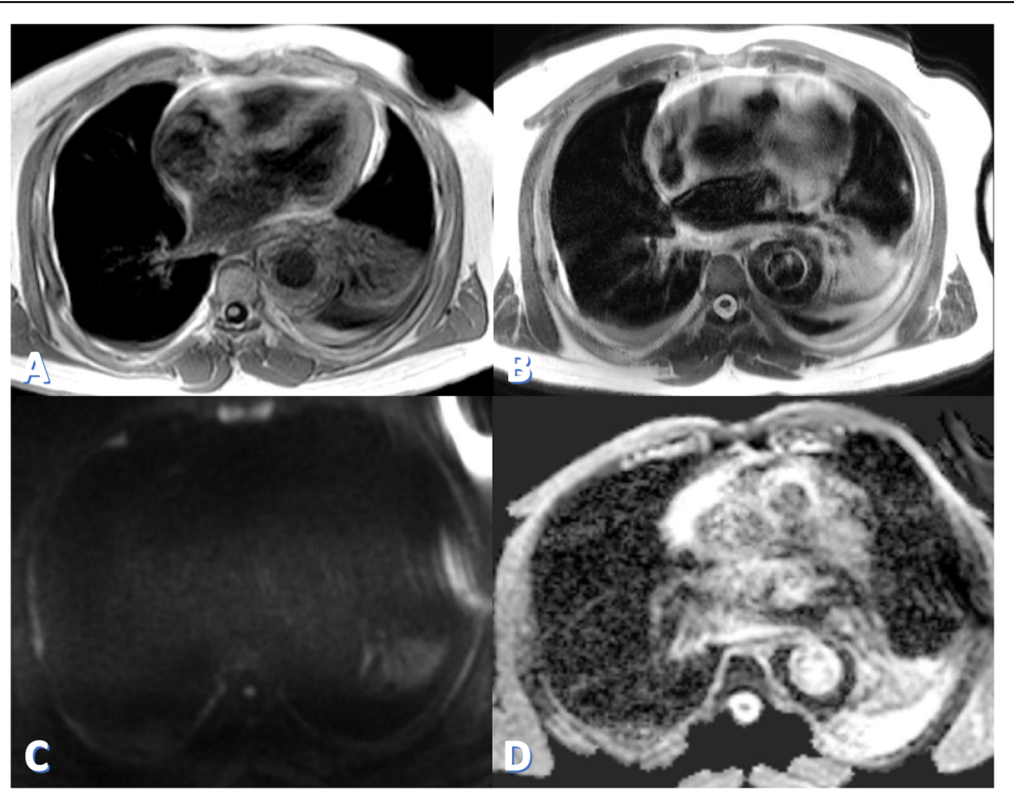

Fig. 2 a Axial T1 WI and $\mathbf{b}$ axial T2 WI showing left encysted pleural effusion displaying high T1 and T2 signal intensities. Associated finding of aortic intramural hematoma is noted eliciting high $\mathrm{T} 1$ and low $\mathrm{T} 2$ signal intensities. $\mathbf{c}$ DWI and $\mathbf{d}$ ADC map showing no evidence of diffusion restriction being bright on $\mathrm{ADC}$ map ( $\mathrm{ADC}$ mean $=2.08 \times 10^{-3} \mathrm{~mm}^{2} / \mathrm{s}$ ). Ultrasound-guided aspiration cytology revealed blood cells (hemothorax) 


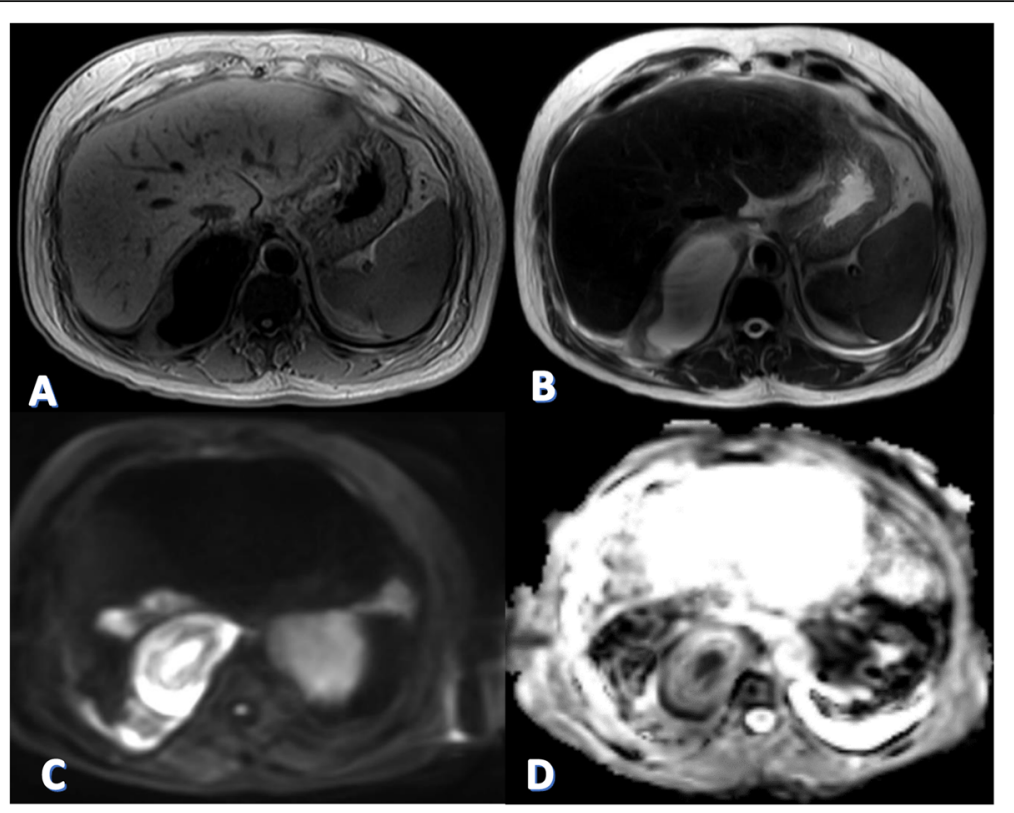

Fig. 3 a Axial T1 WI and $\mathbf{b}$ axial T2 WI showing a well-defined thick-walled multi-locular cystic lesion displaying low T1 and high T2 signal intensities. $\mathbf{c}$ DWI and $\mathbf{d}$ ADC map showing restricted diffusion, with the predominant bright areas on DWI corresponding to dark areas on the ADC map ( $A D C$ mean $=0.82 \times 10^{-3} \mathrm{~mm}^{2} / \mathrm{s}$ ). Ultrasound-guided aspiration cytology revealed pus cells (empyema)

Thirteen $(31.7 \%)$ out of the 41 patients had benign pleural lesions; 1 (7.7\%) patient had pleural lipoma, 2 (15.4\%) had calcified pleural plaques, and $10(76.9)$ had benign pleural thickening, while 28 (68.3\%) patients had malignant pleural lesions; 7 (25\%) patients were diagnosed with malignant pleural mesothelioma (Fig. 4) and 21 (75\%) with pleural metastasis (Fig. 5).

According to imaging findings, lesions were characterized by morphology and signal intensity in conventional sequences in addition to quantitative and qualitative assessment in DWI and ADC maps.

Morphological assessment of the pleural lesions was based on their thickness $(>1 \mathrm{~cm}$ or $<1 \mathrm{~cm}$ ) and contour (smooth or nodular).

Regarding pleural thickness, 28 (68.3\%) lesions were > $1 \mathrm{~cm}$ in maximum thickness and 13 (31.7\%) lesions were $<1 \mathrm{~cm}$.

Nodular contour was also depicted in 28 (68.3\%) lesions, while 13 (31.7\%) lesions showed smooth contour.

Correlation between histopathological diagnosis and imaging findings revealed that 10 (76.9\%) lesions out of the 13 lesions with thickness $<1 \mathrm{~cm}$ were found to be benign and $3(23.1 \%)$ lesions were malignant. On the other hand, from the 28 lesions with thickness $>1 \mathrm{~cm}$, 25 (89.3\%) were malignant and 3 (10.7\%) were benign.

Similarly, 10 lesions out of the 13 (76.9\%) lesions with smooth countour were found to be benign in nature and $3(23.1 \%)$ lesions were malignant, while from the 28 lesions with nodular contour, $25(89.3 \%)$ were malignant and $3(10.7 \%)$ were benign.
Comparing the imaging morphology of the pleural lesions with their histopathological results, MRI was found to be able to discriminate benign from malignant lesions by using morphological features (contour and thickness) with sensitivity $89.29 \%$, specificity $76 \%$, positive predictive value $89 \%$, negative predictive value $76.92 \%$, and accuracy $85.37 \%$.

According to MRI signal intensity, 40 (97.6\%) lesions displayed low $\mathrm{T} 1$, while the remaining fat containing lesion (2.4\%) showed high T1 signal.

In the T2 sequence, 29 (70.7\%) lesions elicited high signal and the other $12(29.3 \%)$ lesions showed low signal, while in the STIR sequence, 28 (68.3\%) lesions displayed high signal and 13 (31.7\%) showed low signal.

Qualitative assessment of the DWI and ADC maps identified 28 (68.3\%) lesions showing diffusion restriction being bright on DWI with corresponding dark area on the ADC map, while 13 (31.7\%) lesions did not show restricted signal in DWI.

All 28 lesions with diffusion restriction were found to be malignant after reviewing their histopathology results, while the other 13 lesions which showed non-restricted signal in DWI were benign.

Pleural lesions ADC mean values ranged from $0.45 \times$ $10^{-3} \mathrm{~mm}^{2} / \mathrm{s}$ to $3.18 \times 10^{-3} \mathrm{~mm}^{2} / \mathrm{s}$ with average $1.45 \pm$ $0.71 \times 10^{-3} \mathrm{~mm}^{2} / \mathrm{s}$.

The malignant pleural lesions showed ADC mean values ranging from $0.45 \times 10^{-3} \mathrm{~mm}^{2} / \mathrm{s}$ to $2.84 \times 10^{-3}$ $\mathrm{mm}^{2} / \mathrm{s}$ with average $1.10 \pm 0.53 \times 10^{-3} \mathrm{~mm}^{2} / \mathrm{s}$, while benign lesions ADC mean values were between $1.80 \times 10^{-3}$ 


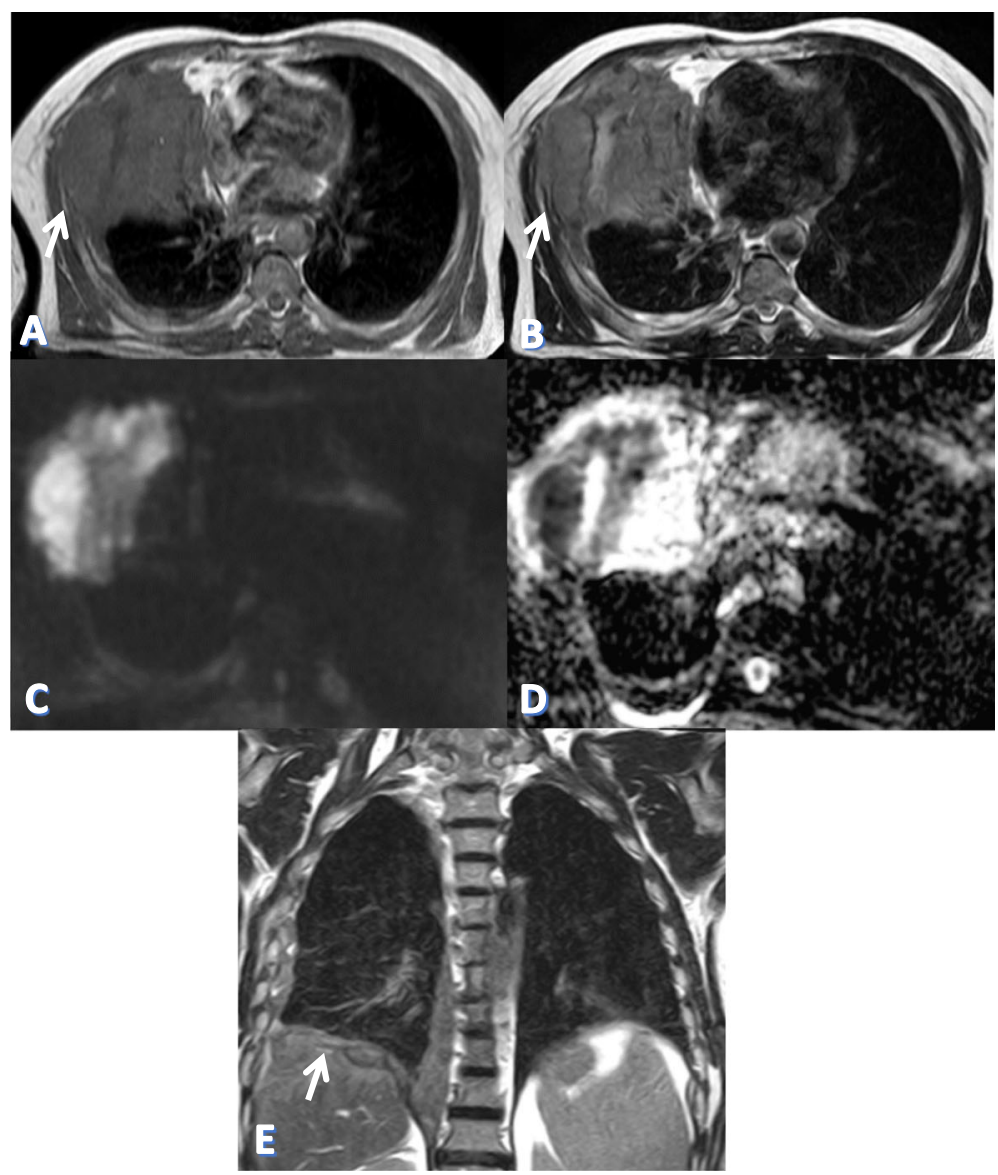

Fig. 4 a Axial T1 Wl, b axial T2 Wl, and e coronal T2 Wl showing right circumferential nodular pleural thickening mounting to mass formation eliciting heterogeneous predominately low $\mathrm{T} 1$ and high $\mathrm{T} 2$ signal intensities with evidence of chest wall and diaphragmatic invasion (white arrows). $\mathbf{c}$ DWI and $\mathbf{d} A D C$ map showing restricted diffusion, with the bright signal on the DWI corresponding to dark signal on the ADC map ( $A D C$ mean $=0.45 \times 10^{-3} \mathrm{~mm}^{2} / \mathrm{s}$ ). CT-guided biopsy revealed malignant pleural mesothelioma

$\mathrm{mm}^{2} / \mathrm{s}$ to $3.18 \times 10^{-3} \mathrm{~mm}^{2} / \mathrm{s}$ with average $2.19 \pm 0.42 \times$ $10^{-3} \mathrm{~mm}^{2} / \mathrm{s}$.

The ADC mean values in patients diagnosed as malignant pleural mesothelioma ranged from $0.45 \times 10^{-3} \mathrm{~mm}^{2} / \mathrm{s}$ to $1.17 \times 10^{-3} \mathrm{~mm}^{2} / \mathrm{s}$ with average $0.84 \pm 0.22 \times 10^{-3} \mathrm{~mm}^{2} / \mathrm{s}$.

In patients diagnosed with pleural metastasis, the ADC mean values ranged from $0.50 \times 10^{-3} \mathrm{~mm}^{2} / \mathrm{s}$ to $2.84 \times$ $10^{-3} \mathrm{~mm}^{2} / \mathrm{s}$ with average $1.19 \pm 0.58 \times 10^{-3} \mathrm{~mm}^{2} / \mathrm{s}$.

Therefore, this study found that the ADC values of malignant pleural diseases were significantly lower than that of benign lesions $(P<0.001)$. However, the ADC mean values of malignant pleural mesothelioma were not significantly different from that of pleural metastasis $(P=0.090)$.

ROC curve analysis revealed that ADC mean value of $1.68 \times 10^{-3} \mathrm{~mm}^{2} / \mathrm{s}$ as a cutoff value can differentiate malignant from benign pleural diseases with sensitivity $89.3 \%$, specificity $100 \%$, positive predictive value $100 \%$, negative predictive value $81.2 \%$, and accuracy $92.68 \%$ with $P$ value $<0.001$ indicating high statistical significance.
The results of morphological and functional assessment to differentiate benign from malignant pleural lesions were compared and illustrated in details in Fig. 6.

Evaluating the associated lymph nodes in patients with malignant pleural mesothelioma showed that 5 patients had intra-thoracic lymph nodes; in $2(40 \%)$ of them, the lymph nodes were $>1 \mathrm{~cm}$, while in the other $3(60 \%)$, the lymph nodes were $\leq 1 \mathrm{~cm}$ and were considered as reactive lymph nodes and not metastatic.

However, all lymph nodes $\leq 1 \mathrm{~cm}$ and $>1 \mathrm{~cm}$ showed restricted signal in DWI.

From the 7 patients diagnosed with malignant pleural mesothelioma, associated osseous erosions were depicted in 2 patients, chest wall invasion in 3 patients and vascular invasion in 1 patient.

\section{Discussion}

Functional MRI of the chest can differentiate malignant from benign conditions by using ADC value as quantitative parameter of DWI [5]. One of the primary 


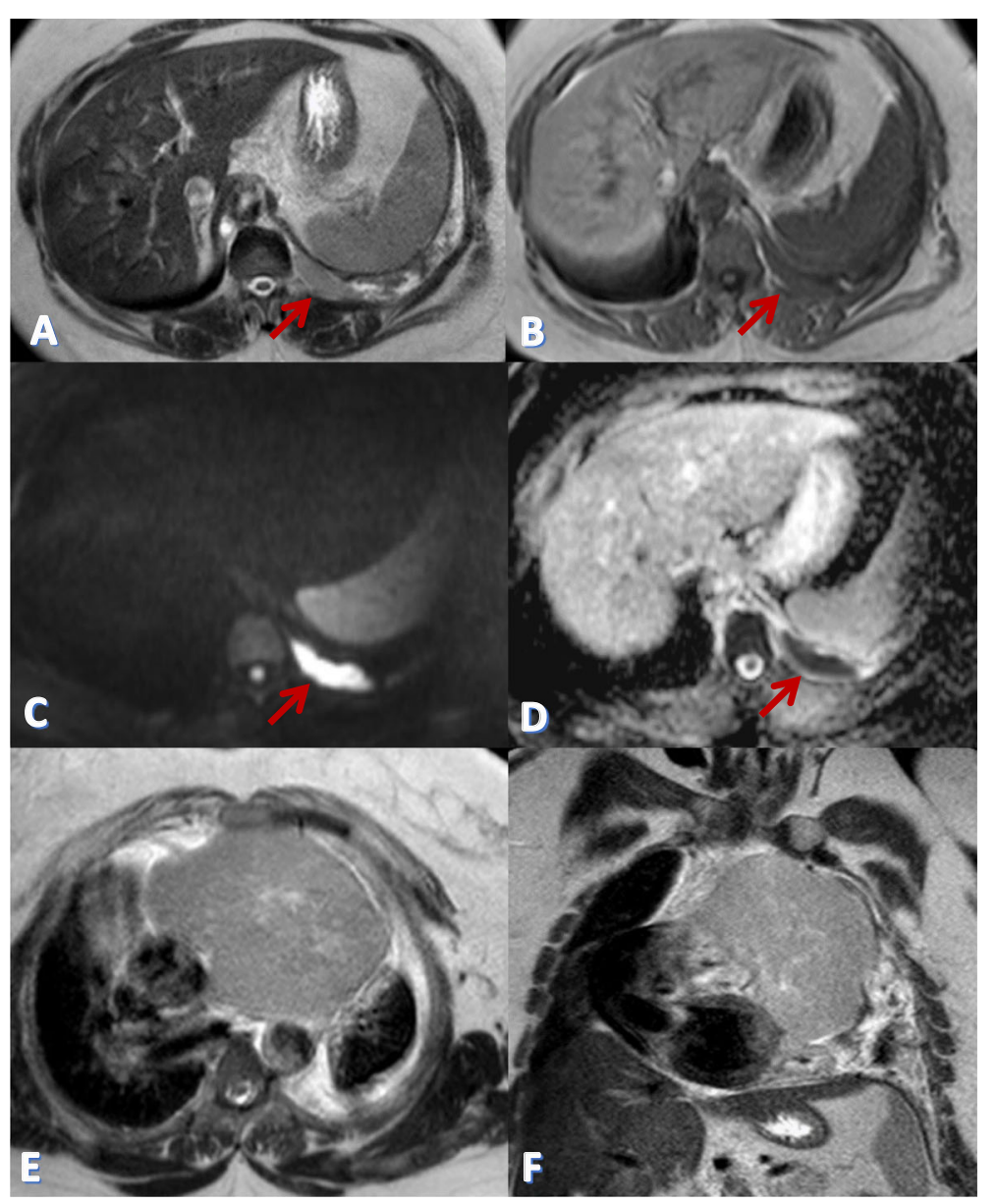

Fig. 5 a Axial T2 WI and $\mathbf{b}$ axial T1 WI showing left focal nodular pleural thickening (red arrows) eliciting low T1 and high T2 signal intensities with left moderate pleural effusion eliciting heterogeneous low T1 and high T2 signal. c DWI and $\mathbf{d}$ ADC map showing restricted diffusion of the pleural thickening with the bright areas on the DWI corresponding to dark areas on the ADC map (red arrows), while the pleural effusion was non-restricted (pleural thickening and effusion showed ADC mean $=0.54 \times 10^{-3} \mathrm{~mm}^{2} / \mathrm{s}$ and $3.07 \times 10^{-3} \mathrm{~mm}^{2} / \mathrm{s}$ respectively). e Axial T2 and $\mathbf{f}$ coronal T2 Wl, showed anterior mediastinal lesion. CT-guided biopsy revealed pleural metastasis from invasive thymoma and malignant pleural effusion

advantages of DWI is the short examination time and the lack of need of contrast injection, so it can be added to the routine MRI sequences without a notable increase in the exam duration [5]. We subdivided pleural lesions according to lesions type into either pleural effusion or pleural thickening and masses. We evaluated the conventional and functional MRI imaging findings of pleural lesions and correlated them to their histopathological results.

Hallifax et al. [3] stated that various benign and malignant conditions can involve the pleura with malignant diseases being more common than benign; this matches the results of our study, where malignant lesions represented more than three quarters of the encountered pleural lesions.

According to signal intensity, almost all the fluid displayed low T1, bright T2, and STIR signal intensities; likewise, Coolen et al. [4] established that pleural fluid typically elicits low T1 signal intensity and high T2 signal intensity, mirroring its water content.

Regarding qualitative assessment of DWI, almost all fluid showed no evidence of diffusion restriction with average ADC mean value of $3.35 \pm 0.78 \times 10^{-3} \mathrm{~mm}^{2} / \mathrm{s}$, which agrees with Usuda et al.'s [9] study where pleural effusion showed average ADC mean value of $3.76 \pm 0.62$ $\times 10^{-3} \mathrm{~mm}^{2} / \mathrm{s}$.

Also, quantitative assessment of the DWI and ADC map recognized no significant difference between ADC mean values of malignant and benign effusion. In consistency with our study, Usuda et al. [9] stated that there is no significant difference in ADC mean values of fluid associated with malignant pleural mesothelioma, pleural metastasis, and benign pleural effusion. Similarly, Karatag et al. [10] found no statistically significant results to differentiate between inflammatory/infectious effusion and malignant effusion. 


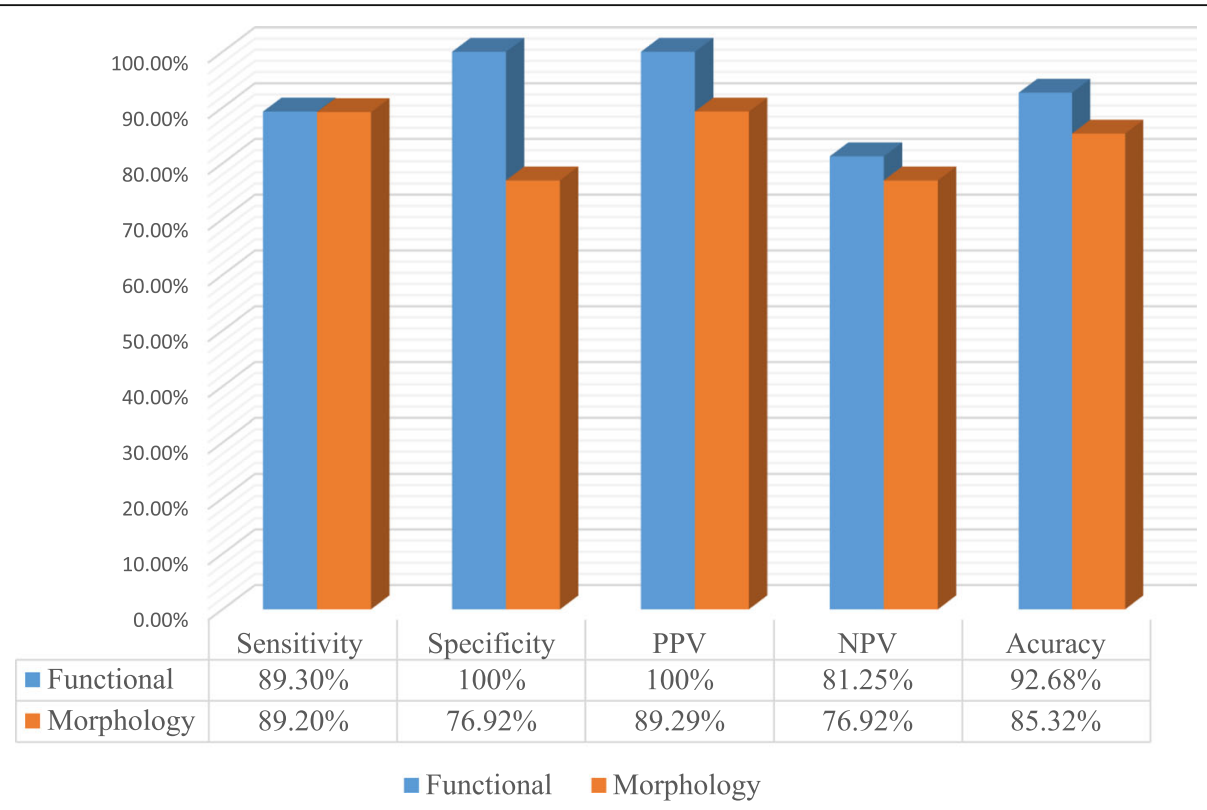

Fig. 6 A chart comparing the results of morphological and functional MRI assessment to differentiate benign from malignant pleural lesions

Wherefore, both conventional and functional MRI could not differentiate between malignant and benign effusion.

In this study, only one patient was diagnosed with empyema where the fluid showed diffusion restriction being low on ADC map with ADC mean value of $0.82 \times 10^{-3}$ $\mathrm{mm}^{2} / \mathrm{s}$ which is much lower than ADC values of fluid with either benign or malignant pleural effusion; this can be explained by hyper-viscous pus content which hinder the diffusivity of water molecules. Due to limited number of empyemas in our study, we could not repeat the results from Usuda et al.'s [9] study which declared that the ADC mean value of pleural fluid in empyema was significantly lower than that in malignant pleural mesothelioma $(P=0.0023)$, pleural metastasis $(P=0.0286)$, and benign pleural effusions $(P=0.0009)$.

Malignant pleural lesions were classified into malignant pleural mesothelioma and pleural metastasis with the latter being more common; this was compatible with Carter et al. [5] who claimed that the most common cause of pleural malignancy is metastatic diseases followed by primary pleural tumors (e.g., malignant pleural mesothelioma).

Regarding the morphological assessment of the pleural lesions, Pena et al., Coolen et al., Hierholzer et al., and Leung et al. [1, 11-13] described several factors that can help in differentiating benign from malignant pleural diseases including pleural thickness, pleural contour, volume of the involved hemi-thorax, and mediastinal or diaphragmatic infiltration.

In this study, pleural thickness $(>1 \mathrm{~cm}$ or $<1 \mathrm{~cm})$ and contour (smooth or nodular) were the two factors used to differentiate benign from malignant pleural diseases as they were the most common factors encountered in literature. Our study results advocated that morphological assessment using MRI can reliably discriminate benign from malignant pleural lesions, with sensitivity $89.29 \%$, specificity $76 \%$, and accuracy $85.37 \%$. In agreement with our study, Coolen et al. [11] used pleural thickening on MRI to discriminate benign from malignant pleural lesions with sensitivity $81 \%$, specificity $73 \%$, and accuracy $78 \%$.

All malignant lesions in our study showed diffusion restriction, denoting their high cellularity with significantly lower average ADC mean value than benign lesions. Similarly, Inan et al. [14] found that the average ADC mean value of malignant pleural thickening to be significantly lower than benign thickening. Moreover, Koç et al. [15] showed significant difference between the average ADC mean value of benign and malignant pleural thickening.

We noticed no significant difference between the average ADC mean value in patients with malignant pleural mesothelioma and in patients with pleural metastasis. This was concordant with Usuda et al.'s [9] results.

Coolen et al. [16] adopted ADC mean value of 1.52 $\times 10^{-3} \mathrm{~mm}^{2} / \mathrm{s}$ as a threshold to differentiate benign from malignant pleural diseases, and showed sensitivity, specificity, and accuracy of $71.4 \%, 100 \%$, and $87.1 \%$, respectively. Our results were more or less similar to this study, where an ADC mean value of $1.68 \times 10^{-3} \mathrm{~mm}^{2} / \mathrm{s}$ was used as a cutoff value to differentiate malignant from benign pleural diseases with higher sensitivity $89.3 \%$ and accuracy $92.68 \%$ and similar specificity $100 \%$. 
Consequently, adding DWI and ADC map to conventional MRI sequences results in higher specificity and accuracy, yet with no difference regarding the sensitivity.

Kruse et al. and Usuda et al. [2, 9] acknowledged one of the pitfalls of functional imaging being the false positive results in inflammatory processes, as it can be misdiagnosed as malignant pathology. Correspondingly, the case of empyema in our study showed low ADC value of $0.82 \times 10^{-3} \mathrm{~mm}^{2} / \mathrm{s}$ which matched the ADC values of malignant lesions, yet it was diagnosed correctly by its morphology on the conventional MRI images.

Our study limitation is the relatively small number of cases, so we recommend further research on a larger population to confirm our results.

\section{Conclusion}

In conclusion, although DWI-MRI is unable to differentiate between malignant and benign pleural effusion, its combined morphological and functional information provide valid non-invasive method to accurately characterize pleural soft tissue diseases differentiating benign from malignant lesions with higher specificity and accuracy than conventional MRI.

\section{Abbreviations \\ ADC: Apparent diffusion coefficient; DWl: Diffusion-weighted images; ROI: Region of interest}

\section{Acknowledgements}

Not applicable.

\section{Authors' contributions}

LTE and MRA reviewed the images. YYS, LTE, and IHM analyzed and interpreted the patient data. SFT wrote the manuscript and YYS reviewed it. All authors have read and approved the manuscript.

\section{Funding}

The authors state that this work has not received any funding.

\section{Availability of data and materials}

The datasets used and/or analyzed during the current study are available from the corresponding author on reasonable request.

\section{Declarations}

Ethics approval and consent to participate

Approval of the ethical committee of the "Radiology department, Faculty of Medicine, Cairo University" was granted before conducting this prospective study; reference number: not applicable.

Local institutional review board approval was granted before conducting this cross sectional study, and written informed consent was obtained from all patients.

\section{Consent for publication}

All patients included in this research gave written informed consent to publish the data contained within this study. If the patients were less than 16 years old, deceased, or unconscious when consent for publication was requested, written informed consent for the publication of this data was given by their parents or legal guardians.

\section{Competing interests}

The authors declare that they have no competing interests.

\section{Author details}

${ }^{1}$ Faculty of Medicine, Cairo University, Kasr Al-Ainy Faculty of Medicine, Al-Manial, Cairo 11559, Egypt. ${ }^{2}$ National Cancer Institute, Kasr Al-Ainy Street, Fom El-Kalig, Cairo 11796, Egypt. ${ }^{3}$ National Institute of Diabetes and Endocrinology, 16 Kasr Al-Ainy Street, El-Sayeda Zainab, Cairo 11783, Egypt.

Received: 17 February 2021 Accepted: 8 July 2021

Published online: 27 July 2021

\section{References}

1. Pena E, Ojiaku M, Inacio JR, Gupta A, Macdonald DB, Shabana W, Seely JM, Rybicki FJ, Dennie C, Thornhill RE (2017) Can CT and MR shape and textural features differentiate benign versus malignant pleural lesions? Acad Radiol 24(10):1277-1287. https://doi.org/10.1016/j.acra.2017.03.006

2. Kruse M, Sherry SJ, Paidpally V, Mercier G, Subramaniam RM (2013) FDG $\mathrm{PET} / \mathrm{CT}$ in the management of primary pleural tumors and pleural metastases. Am J Roentgenol 201 (2):W215-W226. https://doi.org/10.2214/A JR.13.10572

3. Hallifax RJ, Talwar A, Wrightson JM, Edey A, Gleeson FV (2017) State-of-theart: radiological investigation of pleural disease. Respir Med 124:88-99. https://doi.org/10.1016/j.rmed.2017.02.013

4. Coolen J, Verschakelen J, De Wever W (2015) MRI of pleural diseases. Curr Opin Pulm Med 21(4):399-406. https://doi.org/10.1097/MCP. 0000000000000177

5. Carter BW, Betancourt SL, Shroff GS, Lichtenberger JP (2018) MR imaging of pleural neoplasms. Top Magn Reson Imaging 27(2):73-82. https://doi.org/1 0.1097/RMR.0000000000000162

6. Dhanda S, Thakur M, Kerkar R, Jagmohan P (2014) Diffusion-weighted imaging of gynecologic tumors: diagnostic pearls and potential pitfalls. Radiographics 34(5):1393-1416. https://doi.org/10.1148/rg.345130131

7. Qayyum A (2009) Diffusion-weighted imaging in the abdomen and pelvis: concepts and applications. Radiographics 29(6):1797-1810. https://doi.org/1 $0.1148 / \mathrm{rg} .296095521$

8. Subhawong TK, Jacobs MA, Fayad LM (2014) Diffusion-weighted MR imaging for characterizing musculoskeletal lesions. Radiographics 34(5): 1163-1177. https://doi.org/10.1148/rg.345140190

9. Usuda K, Iwai S, Funasaki A, Sekimura A, Motono N, Matoba M, Doai M, Yamada S, Ueda Y, Uramoto H (2019) Diffusion-weighted imaging can differentiate between malignant and benign pleural diseases. Cancers 11(6): 811. https://doi.org/10.3390/cancers 11060811

10. Karatag O, Alar T, Kosar S, Ocakoglu G, Yildiz Y, Gedik E, Gonlugur U, Ozdemir H (2015) Can diffusion weighted magnetic resonance imaging differentiate between inflammatory-infectious and malignant pleural effusions? JBR-BTR 98(2):63-67

11. Coolen J, De Keyzer F, Nafteux P, De Wever W, Dooms C, Vansteenkiste J, Derweduwen A, Roebben I, Verbeken E, De Leyn P, Van Raemdonck D (2015) Malignant pleural mesothelioma: visual assessment by using pleural pointillism at diffusion-weighted MR imaging. Radiology 274(2):576-584. https://doi.org/10.1148/radiol.14132111

12. Hierholzer J, Luo L, Bittner RC, Stroszczynski C, Schoenfeld N, Dorow P, Loddenkemper R, Grassot A (2000) MRI and CT in the differential diagnosis of pleural disease. Chest 118(3):604-609. https://doi.org/10.1378/chest.118.3. 604

13. Leung AN, Müller NL, Miller RR (1990) CT in differential diagnosis of diffuse pleural disease. AJR 154(3):487-492. https://doi.org/10.2214/ajr.154.3.2106209

14. Inan N, Arslan A, Akansel G, Arslan Z, Eleman L, Demirci A (2009) Diffusionweighted MRI in the characterization of pleural effusions. Diagn Interv Radiol 15(1):13-18

15. Koç M, Poyraz AK (2017) The role of diffusion-weighted MR imaging in detecting malignant and benign pleural thickening in asbestos-related pleural diseases. Erciyes Med J/Erciyes Tip Dergisi 39(2):44-47

16. Coolen J, De Keyzer F, Nafteux P, De Wever W, Dooms C, Vansteenkiste J, Roebben I, Verbeken E, De Leyn P, Van Raemdonck D, Nackaerts K (2012) Malignant pleural disease: diagnosis by using diffusion-weighted and dynamic contrast-enhanced MR imaging -initial experience. Radiology 263(3):884-892. https://doi.org/10.1148/radiol.12110872

\section{Publisher's Note}

Springer Nature remains neutral with regard to jurisdictional claims in published maps and institutional affiliations. 